\title{
Gender preference among post-natal women for the next child: A study from coastal south India
}

\author{
Nithin Kumar ${ }^{\mathrm{a}, \mathrm{b}}$, Rekha Thapar ${ }^{\mathrm{a}, \mathrm{b}, *}$, Prasanna Mithra ${ }^{\mathrm{a}, \mathrm{b}}$, Bhaskaran Unnikrishnan ${ }^{\mathrm{a}, \mathrm{b}}$, \\ Kausthubh Hegde ${ }^{c, d}$, K. Nishantha Bhat ${ }^{c, d}$, Noel Rayen ${ }^{c, d}$, Varun Holla ${ }^{c, d}$, Ramesh Holla ${ }^{\mathrm{a}, \mathrm{b}}$, \\ Vaman Kulkarni $^{\mathrm{a}, \mathrm{b}}$, Darshan Bhagawan ${ }^{\mathrm{a}, \mathrm{b}}$, Avinash Kumar ${ }^{\mathrm{a}, \mathrm{b}}$ \\ ${ }^{a}$ Department of Community Medicine, Kasturba Medical College, Mangalore, India \\ ${ }^{\mathrm{b}}$ Faculty of Health Sciences, Manipal Academy of Higher Education, Manipal, India \\ ${ }^{\mathrm{c}}$ Kasturba Medical College, Mangalore, India \\ ${ }^{\mathrm{d}}$ Manipal Academy of Higher Education, Manipal, India
}

\section{A R T I C L E I N F O}

\section{Keywords:}

Gender preferences

Family composition

Sex -ratio

Postnatal women

South India

\begin{abstract}
A B S T R A C T
A balanced sex ratio is important for a stable society. However, son preference and discrimination towards the female gender has resulted in an adverse sex ratio. The objective of this cross sectional study was to assess the preference of women in post natal period, regarding gender of their next child. In this hospital based study 155 post-natal women from two tertiary care hospitals of Mangalore, in Karnataka State, India were interviewed using a semi-structured questionnaire. Data was analyzed using Statistical Package for Social Sciences (SPSS) version 25.0. Of the study participants, $41.3 \%(n=64)$ were in the age group between 23 and 27 years. Majority ( $n=115,72.9 \%$ ) of the women preferred having two children. Among the 76 post-natal women with male newborn child, $52.6 \%(n=40)$ wanted their next child to be a female. While among 79 post-natal women with a female newborn child, $69.6 \%(n=55)$ wanted their next child to be a male. The overall son preference index in our study was 1.6 which showed strong tendency towards son preference. As son preference still prevails in our community, it is necessary to educate people regarding the adverse outcomes of an imbalanced society and its consequences.
\end{abstract}

\section{Introduction}

Sex ratio at birth, defined as 'the number of females per thousand males' is an important indicator to assess the balance for a stable society. It is one of the many indications of the extent of prenatal sex selection. ${ }^{1}$ Indian census has shown a marked gap between the number of men and women. Low female counts are due to the difference in the mortality rate, migration, sex-ratio at birth and under-counting of women during Census. ${ }^{2}$ High maternal mortality, female infanticide, sex-selective abortion and neglect of the girl child at a young age have also contributed to a skewed sex ratio. Differential treatment given to the women in our society has led to many sex-selective abortions. ${ }^{3}$

Preference of the male child has also distorted the natural scale of equal number of males and females in the society. Sons have been preferred since ancient times as they earn higher wages, continue the family line and were generally the recipients of inheritance, whereas daughters have always been considered a financial burden because of the dowry system. ${ }^{4}$ For women who have little control over economic resources in a family, the only way to contribute to the family is assumed to be by giving birth to male children. Sex-ratio over the past 10 years in India has shown significant improvement. Though it has increased from 933 in 2001 to 940 in 2011, it is still low.

Right to equality is a fundamental right of every citizen of India irrespective of their gender. Thus, women deserve equal respect and opportunities in our society and the government has passed several laws in this regard. The Indian government plays a vital role in empowering the girl child by implementing various schemes and programs which aim at changing the negative attitude of the society and communities towards the girl child. These schemes and programs also help in increasing the enrolment and retention of girls in schools, raising the

\footnotetext{
* Corresponding author. Department of Community Medicine, Kasturba Medical College, Mangalore, India.

E-mail addresses: nithin.gatty@manipal.edu (N. Kumar), rekha.thapar@manipal.edu (R. Thapar), prasanna.mithra@manipal.edu (P. Mithra), unnikrishnan.b@manipal.edu (B. Unnikrishnan), hegdekausthubh@gmail.com (K. Hegde), nishanthabhatk@gmail.com (K.N. Bhat),

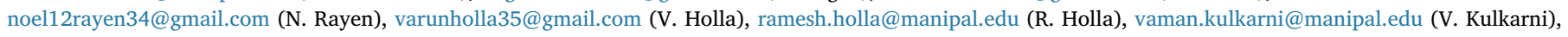
darshan.bb@manipal.edu (D. Bhagawan), avinash.kumar@manipal.edu (A. Kumar).
} 
legal age of marriage among girls and creating more income opportunities. - Balika Samridhi Yojana, Sukanya Samridhi Yojana to name a few. ${ }^{5,6}$ Despite all these initiatives, the age-old mentality of considering females inferior or a burden still prevails in our society.

Mangalore city in Dakshina Kannada district, where the current study was conducted has a favorable sex-ratio of 1016 women per 1000 men. But the sex ratio at birth in this region has dropped from 960 in 2001 to 941 in 2011. ${ }^{7}$ Although Mangalore has a high female literacy rate with most of the communities following a matriarchal system of inheritance, the report of adverse sex ratio from this region is alarming. ${ }^{8}$

With this background the current study was conducted to assess the preference for the gender of their next child among the postnatal women admitted in health care centers.

\section{Methodology}

This hospital based cross sectional study was conducted in the city of Mangalore which is the chief port city and administrative headquarters of Dakshina Kannada district in the Indian State of Karnataka, with a population of $6,23,841$ and a female literacy rate of $91.63 \%{ }^{7}$ It is one of the major healthcare centers in Karnataka with more than 10 tertiary care centers including centers purely catering to maternal and child health care such as Lady Goschen hospital which is a government referral center catering to a large population of all religious and socioeconomic background from both within and outside the district. This study was conducted among 155 postnatal women admitted in two teaching hospitals associated with Kasturba Medical College, Mangalore in the month of March 2017. It was a time bound study. Institution Ethics Committee clearance was obtained, and due permission was sought from the Medical Superintendents of both hospitals before the commencement of the study. A questionnaire was designed and translated to the local language (Kannada). The nature and purpose of the study was explained to the participants. After obtaining written informed consent, the women were interviewed by the investigators. Women who had conceived at least once irrespective of the outcome of the pregnancy were included in the study. The questionnaire was divided into two sections. Section A - socio-demographic characteristics, and section $\mathrm{B}$ - fertility profile and gender preference of children. The socio-economic status of the participants was assessed using the modified BG Prasad Scale. ${ }^{9}$ For further analysis, middle, upper middle and upper class were combined to form a category of high socio economic status, while lower and lower middle class were combined to form low socio-economic status.

Data was analyzed using Statistical Package for Social Sciences (SPSS) software version 25.0. Results are presented in terms of proportions, and mean (Standard Deviation). Univariate analysis was done using the Chi-square test. Son Preference Index was calculated using the following equation: ${ }^{10,11}$

SPI $=\frac{\text { Number of women who preferred the next child to be male }}{\text { Number of women who preferred next child to be female }}$

\section{Results}

A total of 155 women in their postnatal period were included in our study. A higher proportion of the participants $(n=69,44.5 \%)$ were aged 28 years or more, and belonged to middle socio-economic status ( $\mathrm{n}=63,40.6 \%$ ). Majority of our participants were Hindus, homemakers and had completed their secondary school education. Most i.e. $75(48.4 \%)$ of the respondents belonged to a joint family.

Among the study participants, $56.8 \%$ had one child ( $\mathrm{n}=88$ ), $34.2 \%$ had two children $(n=53)$ and $9.0 \%(n=14)$ had more than two children. The socio-demographic profile of the respondents and son preference index is shown in Table 1. The overall son preference index (SPI) in our study was 1.6. Son preference index was higher among
Table 1

Socio-demographic characteristics of the study participants $(\mathrm{N}=155)$.

\begin{tabular}{lll}
\hline Sociodemographic Characteristics & $\mathrm{n}(\%)$ & Son Preference Index (SPI) \\
\hline Age group (years) & & \\
$\leq 22$ & $22(14.2)$ & 2.50 \\
23 to 27 & $64(41.3)$ & 1.35 \\
$\geq 28$ & $69(44.5)$ & 1.69 \\
Religion & & \\
Hindu & $137(88.4)$ & 1.58 \\
Muslim & $014(09.0)$ & 2.00 \\
Christian & $004(02.6)$ & 1.00 \\
Educational Status & & \\
Illiterate & $04(02.6)$ & 3.00 \\
Primary school & $21(13.5)$ & 1.14 \\
Secondary school (SSLC) & $86(55.5)$ & 1.89 \\
Pre-University College & $23(14.8)$ & 1.00 \\
Graduation & $19(12.3)$ & 2.00 \\
Post-Graduation & $02(01.3)$ & 0.00 \\
Occupation & & \\
Homemaker & $107(69.0)$ & 1.41 \\
Unskilled worker & $27(17.4)$ & 2.17 \\
Semi-skilled worker & $14(09.0)$ & 2.33 \\
Professional worker & $07(04.5)$ & 1.50 \\
Socioeconomic status & & \\
Lower class & $05(03.2)$ & 1.50 \\
Lower middle class & $51(32.9)$ & 1.77 \\
Middle class & $63(40.6)$ & 1.71 \\
Upper middle class & $35(22.6)$ & 1.40 \\
Upper class & $01(00.6)$ & 0.00 \\
& & \\
& & \\
& &
\end{tabular}

younger women under the age of 22, Muslims and unskilled/semiskilled workers. Gender preference was present in almost every socio-economic group, but no consistent relationship could be established between economic status of women and their gender preference.

Perception regarding ideal family size and gender preference among the study participants is shown in Table 2. Majority ( $\mathrm{n}=113,72.9 \%$ ) respondents preferred to have two children. The women who wanted more than two children alluded economic stability of the family as the reason for their preference. Sixty percent $(n=93)$ of the participants preferred equal number of male and female children (1:1 ratio). Very few women $(n=10,6.4 \%)$ preferred to have more number of female children compared to male children. Among the 76 post-natal women with male newborn child, $52.6 \%(n=40)$ wanted their next child to be a female. While among 79 post-natal women with a female newborn

Table 2

Perception about Ideal Family Size and Gender Preference among the study participants. $(\mathrm{N}=155)$.

\begin{tabular}{lc}
\hline Responses & $\mathrm{n}(\%)$ \\
\hline Ideal number of children in a family $(\mathbf{N}=\mathbf{1 5 5})$ & \\
1 & $011(07.1)$ \\
2 & $113(72.9)$ \\
More than 2 & $031(20.0)$ \\
Ideal combination $(\mathbf{N}=\mathbf{1 5 5})$ & \\
No. of Males = No. of Females & $93(60.0)$ \\
Males > Females & $19(12.3)$ \\
Females > Males & $10(06.4)$ \\
Only Males & $06(03.9)$ \\
Only Females & $02(01.3)$ \\
No preference & $25(16.1)$ \\
Gender preference of the next child if present child is a male $(\mathbf{N}=\mathbf{7 6})$ \\
Boy & $12(15.8)$ \\
Girl & $40(52.6)$ \\
No preference & $19(25.0)$ \\
No second child & $05(06.6)$ \\
Gender preference of the next child if present child is a female $(\mathbf{N}=\mathbf{7 9})$ \\
Boy & $55(69.6)$ \\
Girl & $02(02.5)$ \\
No preference & $21(26.6)$ \\
No second child & $01(01.3)$ \\
& \\
&
\end{tabular}


Table 3

Perception of study participants regarding their own gender $(\mathrm{N}=155)$.

\begin{tabular}{lc}
\hline Perception About Their Gender & $\mathrm{n}(\%)$ \\
\hline $\begin{array}{l}\text { Number of respondents who felt that they should not have been a girl } \\
\quad \text { child. }\end{array}$ & $39(25.2)$ \\
Reasons for Preferring to be Born as Males $(\mathbf{n}=\mathbf{3 9})$ & \\
Life as a woman is difficult & $28(71.8)$ \\
Fear and insecurity & $04(10.3)$ \\
Dowry and marriage expenses & $02(05.1)$ \\
Increasing number of crimes against women & $03(07.7)$ \\
Others & $02(05.1)$ \\
Reasons for Preferring to be Born as Females $(\mathbf{n}=\mathbf{1 1 6})$ & $68(58.6)$ \\
Have equal rights as a woman & $44(37.9)$ \\
Being a mother is an honor & $04(03.4)$ \\
\hline
\end{tabular}

child, $69.6 \%(n=55)$ wanted their next child to be a male (see Table 3).

When asked about their perception on belonging to a female gender, lower number ( $\mathrm{n}=39,25.2 \%)$ of the respondents preferred not to have been born as a girl child. The reasons cited for this preference included difficult life of a woman, fear and insecurity, dowry and marriage expenses, increasing number of crimes against women etc. However on the contrary majority $(n=116,74.8 \%)$ were happy about their gender status.

Among the study participants who were aware about female feticide ( $n=135,87.1 \%$ ), a higher proportion $(n=57,42.2 \%)$ of them perceived burden of having a girl child as the possible reason for female feticide. Of the 155 respondents, 66 (42.6\%) were aware about the different methods for sex determination, the most common method being ultrasonography. Awareness of female feticide among the respondents is shown in Table 4.

Table 5 shows the factors affecting son preference among study participants. Son preference was higher among mothers $\leq 27$ years of age $(n=19,22.1 \%)$ belonging to urban area $(n=25,21.4 \%)$, high socio-economic status ( $\mathrm{n}=21,21.2 \%)$, non-nuclear families $(\mathrm{n}=23$, $21.5 \%)$ and among mothers who did not have a male child $(n=15$, $22.7 \%)$. However, none of these factors were found to be statistically significant $(\mathrm{P}>0.05)$.

\section{Discussion}

Most communities in India have been patriarchal since ancient times. Sons play a key role in most rites and rituals in our society. The male dominant society of India makes the women bear the brunt of this discrimination. It is ironic that in a country where women deities are worshipped reverently, the women are looked down upon by the society. Communities prefer males as it is assumed that sons will provide support in old age, continue the name of the family and usually inherit the property. Women on the other hand, are considered an economic burden because of the dowry system. Even when not disastrous, inclination towards having sons can result in gender-based inequality which manifests itself in the form of discrimination against daughters in providing education, healthcare and nutrition which in turn increases

Table 4

Awareness of female feticide among study respondents $(\mathrm{N}=155)$.

\begin{tabular}{ll}
\hline Awareness about Female Feticide & $\mathrm{n}(\%)$ \\
\hline Aware & $135(87.1)$ \\
Unaware & $20(12.9)$ \\
Perceived Reasons for Feticide $(\mathbf{n}=\mathbf{1 3 5})$ & \\
Burden of having a girl child & $57(42.2)$ \\
Dowry & $38(28.1)$ \\
Poverty & $23(17.0)$ \\
Family pressure & $17(12.6)$
\end{tabular}

Table 5

Factors affecting son preference among study participants $(\mathrm{N}=155)$

\begin{tabular}{|c|c|c|c|c|}
\hline \multirow[t]{3}{*}{ Variables } & \multicolumn{2}{|c|}{ Son Preference } & \multirow[t]{3}{*}{ Total } & \multirow[t]{3}{*}{ Chi Square P value } \\
\hline & Yes $\mathrm{N}=32$ & No $\mathrm{N}=123$ & & \\
\hline & N (\%) & $\mathrm{N}(\%)$ & & \\
\hline \multicolumn{5}{|c|}{ Age group (yrs) } \\
\hline$\leq 27$ & $19(22.1)$ & $67(77.9)$ & 86 & 0.247 \\
\hline$>27$ & $13(18.8)$ & $56(81.2)$ & 69 & $\mathrm{P}>0.05$ \\
\hline \multicolumn{5}{|l|}{ Religion } \\
\hline Hindu & 27 (19.7) & $110(80.3)$ & 137 & 2.183 \\
\hline Muslim & $03(21.4)$ & $011(78.6)$ & 14 & $\mathrm{P}>0.05$ \\
\hline Christian & $02(50.0)$ & $002(50.0)$ & 04 & \\
\hline \multicolumn{5}{|c|}{ Place of Residence } \\
\hline Rural & $07(18.4)$ & $31(81.6)$ & 38 & 0.152 \\
\hline Urban & $25(21.4)$ & $92(78.6)$ & 117 & $\mathrm{P}>0.05$ \\
\hline \multicolumn{5}{|c|}{ Socio economic status } \\
\hline Low & $11(19.6)$ & $45(80.4)$ & 56 & 0.054 \\
\hline High & $21(21.2)$ & $78(78.8)$ & 99 & $\mathrm{P}>0.05$ \\
\hline \multicolumn{5}{|l|}{ Family Type } \\
\hline Nuclear & $09(18.8)$ & $39(81.3)$ & 48 & 0.152 \\
\hline Non- Nuclear ${ }^{a}$ & $23(21.5)$ & $84(78.5)$ & 107 & $\mathrm{P}>0.05$ \\
\hline \multicolumn{5}{|c|}{ Total Number of children } \\
\hline 1 & $19(21.8)$ & $68(78.2)$ & 87 & 0.173 \\
\hline$>1$ & $13(19.1)$ & $55(80.9)$ & 68 & $\mathrm{P}>0.05$ \\
\hline \multicolumn{5}{|c|}{ Having a male children } \\
\hline Yes & $17(19.1)$ & $72(80.9)$ & 89 & 0.304 \\
\hline No & $15(22.7)$ & $51(77.3)$ & 66 & $\mathrm{P}>0.05$ \\
\hline \multicolumn{5}{|c|}{ Having a female child } \\
\hline Yes & $21(20.6)$ & $81(79.4)$ & 102 & 0.001 \\
\hline No & $11(20.8)$ & $42(79.2)$ & 53 & $\mathrm{P}>0.05$ \\
\hline
\end{tabular}

${ }^{\text {a }}$ Includes joint and three generation families.

the problems faced by the girl child. Even though few communities of Mangalore are known to be matriarchal, gender preference for a male child still exists. This is a matter of concern in our society.

Our study revealed that gender preference exists among women of all socioeconomic status to some extent. Most women wished for at least one son in the family. One can speculate that this son preference may lead to the neglect of the girl child in her infancy and childhood or may also lead to sex selective abortions and female infanticide.

Son preference of the next child in our study was reported among $43.2 \%$ respondents. Region-wise variation in son preference has been reported by various studies in India. In a study conducted by Dey Pal I and Chaudhuri RN in rural West Bengal, son preference was $39.2 \%{ }^{12}$ while a higher preference for sons $(50.2 \%)$ was reported by Dudeja $\mathrm{P}$ et al., in 2013 in Pune. ${ }^{13}$ Another study done by Edmeades $\mathrm{J}$ et al. in Bangalore, Karnataka also revealed that $62.2 \%$ of the women wished for at least one son in the family. ${ }^{14}$ All these studies help us to establish our argument that son preference is still prevalent in India.

In our study the preference for a male child was not limited to women of lower economic status. This is in contrast to the review by Ahmed $\mathrm{N}^{15}$ and Pande RP and Astone NM done in India. ${ }^{16}$ The overall son preference index in our study was 1.6, which is higher than the son preference index (1.3) in a similar study done by Kumar Nithin et al. ${ }^{11}$ in Mangalore among antenatal women. This higher son preference in our study could be attributed to the post natal women knowing the gender of the delivered child. Both studies showed that working women, especially unskilled and semi-skilled workers preferred male children as compared to housewives. This could possibly be due to the pay gap between the two genders.

Muslims had a higher SPI as compared to Hindus and Christians which was similar to the results obtained by Kanyadi S and Kulkarni R in their study in Belagavi ${ }^{17}$ and by Asghar $\mathrm{M}$ et al. ${ }^{18}$ who conducted a study among Manipuri Muslims. The probable reason could be their minority status and the overall lower education levels of the females among the Muslim population. ${ }^{19}$ The woman is given more respect by her husband and the family, and a higher status by the society if she 
gives birth to a male child. This might also be a contributing factor to the son preference.

Majority of respondents in our study (72.9\%) felt that two is the ideal number of children in a family which is in concurrence to the results obtained in studies by Dhande VS et al. in Maharashtra ${ }^{20}$ and Puri et al. in Chandigarh. ${ }^{21}$ The Government of India promotes two child norm to reduce the population of the country. ${ }^{22}$ A Net Reproductive Rate of 1 is one of the targets the government has set to achieve this goal. The total fertility rate of India in 2015 was 2.3 and Net Reproductive Rate (NRR) was 1.1. ${ }^{23}$ This preference for two children or less will be beneficial to the country with concerns of rapidly expanding population. An increase in the number of children will contribute to the ever rising population.

The preferred ideal gender combination of children of the respondents in our study was equal number of males and females (60\%). It was followed by respondents who wanted a greater number of male children $(12.3 \%)$ followed by $6.4 \%$ preferring more female children. Only $3.9 \%$ and $1.3 \%$ women preferred only males and only females respectively. These findings are similar to the study done by Bangal VB and Giri PA in central India. ${ }^{24}$ Sons play an important role in the funeral rites among Hindus and are usually the recipients of property in most communities in India. The reason for son preference in our study was mostly economic, psychological and social as stated in the study done by A-H. El-Gilany and E. Shady in Mansoura, Egypt. ${ }^{10}$

Only $2.5 \%$ respondents preferred their next child to be female if their newborn was a female which is similar to the results obtained by Kalhan $\mathrm{M}$ et al. in Rohtak, Haryana ${ }^{25}$ and a study done by Puri S et al. in Chandigarh. ${ }^{21}$ A study done in Bangladesh by Rahman M and DaVanzo $\mathrm{J}$ showed contradictory finding where many women preferred daughters. ${ }^{26}$ The burden of expenses of marriage usually falls on the family of the bride. Practice of dowry is also very common. Hence this finding in our study is probably because females are considered an economic burden.

In our study, $42.6 \%$ of the respondents were aware of prenatal methods of sex determination which is similar to the findings obtained by Roy A and Biswas R in rural Darjeeling. ${ }^{27}$ Another study conducted by Mahaur $\mathrm{G}$ et al. in coastal Karnataka ${ }^{28}$ showed that $62 \%$ of their respondents were aware of the same. None of the respondents in our study were aware about the gender before the birth of the child. The Government of India passed the Pre-Conception and Pre-Natal Diagnostic Techniques Act (PCPNDT) in 1994 to ban and punish prenatal sex screening and female feticide. ${ }^{29}$

The son preference index in our study was 1.6, which could indicate a possibility of a skewed sex ratio in the future. This skewed sex ratio can manifest in many ways. In a study conducted by Diamond-Smith N, Rudolph $\mathrm{K}$ they found that a skewed sex ratio increases risk for violence against women. ${ }^{30}$

A number of socio cultural factors influence the preference of having a male child in different settings. In our study, son preference was found to be higher among the younger mothers, mothers belonging to urban areas, higher socio-economic status, non-nuclear families and who did not have a male child before. The higher son preference among the urban mothers in our study could be attributed to the fact that most of the study participants were from the urban area. In contrast, a higher son preference was seen among rural mothers in Studies conducted by Bhattacharjya H, Das S and Mog C in Agartala ${ }^{31}$ and by Chavada M and Bhagyalaxmi A in Ahmedabad. ${ }^{32}$ The mothers without sons had a higher son preference in our study. A higher son preference among the mothers with previous girl child has also been reported in other studies. ${ }^{10,17,27,31}$ A study conducted by Bhattacharjya H, Das S and Mog C in Agartala revealed son preference was to be more among the rural mothers, illiterate, women with no male child and those belonging to joint families. ${ }^{31}$ Chavada $\mathrm{M}$ and Bhagyalaxmi $\mathrm{A}$ in their study conducted in Ahmedabad found son preference to be more among the rural mothers and those from joint families. ${ }^{32}$ In a study conducted by ElGilany AH and Shady E in Egypt, son preference was seen among mothers with only girl child and those having illiterate husbands. ${ }^{10}$ Son preference was found to be more among mothers having a female child in a study done by Kanyadi S and Kulkarni R in Belgavi. ${ }^{17}$ In a study by Asghar M, Murry B et al. son preference was seen among mothers belonging to higher socio economic status. ${ }^{18}$ Roy A and Biswas $\mathrm{R}$ in a study conducted in West Bengal reported a higher son preference among younger mothers between 18 and 24 years of age, mothers belonging to lower socio economic status and mothers who did not have a male child. ${ }^{27}$

\section{Conclusions}

Gender preference still prevails in our region. The ideal number of children according to most of the respondents was two, one being a male and the other a female. The overall son preference index was 1.6 which shows a strong son preference. Most common reason for son preference was that a male child would continue the family line and would provide with economic support. The Indian government has time and again tried to focus on preventing sex-selective abortions due to these reasons. No woman interviewed knew the gender of the child before its birth. It is important to create awareness, mostly among women in the society to restore the natural sex ratio.

\section{Financial disclosures}

None.

\section{Details of ethical approval}

Ethics Committee approval was obtained from the Institutional Ethics Committee of Kasturba Medical College, Mangalore, Manipal Academy of Higher Education, Manipal, India prior to the commencement of the study.

\section{Declaration of competing interest}

The authors have declared that no competing interests exist.

\section{Acknowledgement}

The authors would like to thank the participants of the study. We would also like to thank the Department of Community Medicine, Kasturba Medical College, Mangalore and Manipal Academy of Higher Education, Manipal for the support extended for the conduct of the study and encouraging research and its publication in International Journals of repute.

\section{References}

1. Coney NS, Mackey WC. The woman as final arbiter: a case for the facultative character of the human sex ratio. J Sex Res. 1998;35(2):169-175.

2. Census of India [Internet]. New Delhi: Office of the Registrar general and census Commissioner, India. Ministry of Home Affairs, Government of India; [last updated 2019 Jan15. [cited 2019 Jan 16]. Available from: http://censusindia.gov.in/Census And_You/gender_composition.aspx.

3. DTE Staff. India witnesses one of the highest female infanticide incidents in the world: study. Down to Earth. [Internet]. 2018 Sep 19 [cited 2019 Jan 20]. Available from: https://www.downtoearth.org.in/news/health/india-witnesses-one-of-thehighest-female-infanticide-incidents-in-the-world-54803.

4. Diamond-Smith N, Luke NK, McGarvey S. 'Too many girls, too much dowry': son preference and daughter aversion in rural Tamil Nadu, India. Cult Health Sex. 2008;10(7):697-708.

5. Childline India Foundation [Internet]. [Last updated 2019 Jan 29]. Balika Samriddhi Yojana (BSY); [cited 2019 Jan 22]. Available from: http://childlineindia.org.in/ Child-Targeted-Schemes-Programmes.html.

6. National Portal of India [internet]. National Informatics Centre (NIC), Ministry of electronics \& Information Technology, Government of India; [Last updated 2019 Jan 29]. Sukanya Samriddhi Yojna; [cited 2018 May 12]. Available from: https://www. india.gov.in/sukanya-samriddhi-yojna.

7. Population Census 2011 [Internet]. [Last updated on 2015]. Mangalore city census 2011 data; [cited 2018 Apr 30]. Available from: http://www.census2011.co.in/ 
census/city/451-mangalore.html.

8. Staff correspondent. Alarming drop in sex ratio in Dakshina Kannada. The Hindu [Internet] 2012 Nov 7 [last updated 2016 Aug 16] [cited 2018 Apr 22]. Available from: http://www.thehindu.com/news/cities/Mangalore/alarming-drop-in-sexratio-in-dakshina-kannada/article4073514.ece.

9. Singh T, Sharma S, Nagesh S. Socio-economic status scales updated for 2017. Int J Res Med Sci. 2017;5:3264-3267.

10. El-Gilany AH, Shady E. Determinants and causes of son preference among women delivering in Mansoura, Egypt. East Mediterr Health J. 2007;13(1):119-128.

11. Kumar N, Kanchan T, Unnikrishnan B, et al. Gender preferences among antenatal women: a cross-sectional study from coastal South India. Afr Health Sci. 2015;15(2):560-567.

12. Dey Pal I, Chaudhuri RN. Gender preference and its implications on reproductive behavior of mothers in a rural area of West Bengal. Indian J Community Med. 2009;34(1):65-67.

13. Dudeja P, Singh A, Jindal A Bhatnagar N. Preference for male child in two semi urban communities of Pune. J Postgrad Med Educ Res. 2013;47(3):144-147.

14. Edmeades J, Pande RP, Falle T, Krishnan S. Son preference and sterilization use among young married women in two slums in Bengaluru city, India. Glob Public Health. 2011;6(4):407-420.

15. Ahmad N. Female feticide in India. Issues Law Med. 2010;26(1):13-29.

16. Pande RP, Astone NM. Explaining son preference in rural India: the independent role of structural versus individual factors. Popul Res Policy Rev. 2007 Feb;26:1-29.

17. Kanyadi S, Kulkarni R. Determinants of gender preference among women of Belagavi: a cross sectional study. Int J Community Med Public Health. 2017 Dec;4(12):4733-4737.

18. Asghar M, Murry B, Saraswathy KN. Fertility behaviour and effect of son preference among the Muslims of Manipur, India. J Anthropol. 2014;2014:1-5.

19. Bano F. Educational status of Muslim women in India: an overview. IOSR J Humanit Soc Sci. 2017 June;22(06):10-13.

20. Dhande VS, Gadekar RD, Shingare AD, Domple VK. Gender preference among reproductive age group women in rural area. Int J Community Med Public Health. 2016 July;3(7):1862-1865.
21. Puri S, Bhatia V, Swami HM. Gender preference and awareness regarding sex determination among married women in slums of Chandigarh. Indian J Community Med. 2007;32:60-62.

22. Dr Ramesh Pokhriyal. The promotion of two child norm bill [internet]. Lok Sabha, Bill No. 32; 2015. [Cited 2018 Jun 29]. Available from: http://164.100.24.219/ BillsTexts/LSBillTexts/AsIntroduced/4366LS.pdf.

23. Census of India [Internet]. New Delhi: Office of the Registrar general and census Commissioner, India. Ministry of Home Affairs, Government of India; [last updated 2019 Jan 15]. SRS statistical report 2015, Figures at a glance, India-2015; [cited 2018 Jun 29]. Available from: http://www.censusindia.gov.in/vital_statistics/SRS Report_2015/2.\%20Figures\%20at_a_glance_2015.pdf.

24. Bangal VB, Giri PA. Sex combination of living children at the times of sterilization among rural women of central India. Int J Biomed Adv Res. 2012;2(3):63-67.

25. Kalhan M, Singh S, Parkash J, Sharma N, Jangra A, Singh S. Gender preference and fertility intentions amongst reproductive age females in an urban area of district Rohtak (Haryana). Int J Res Dev Pharm Life Sci. 2015 Oct-Nov;4(6):1846-1851.

26. Rahman M, DaVanzo J. Gender preference and birth spacing in Matlab, Bangladesh. Demography. 1993 August;30(3):315-332.

27. Roy A, Biswas R. A study on gender preference and awareness regarding prenatal sex determination among antenatal women in a rural area of Darjeeling district, West Bengal, India. J Clin Diagn Res. 2017 Feb;11(2):5-8.

28. Mahaur G, Badiger S, Shetty SM. Knowledge and attitude of men towards sex determination and PCPNDT act in the field practice area of a medical college in coastal Karnataka. Int. J Community Med Public Health. 2017 Aug;4(8):2192-2198.

29. Bhaktwani A. The PC-PNDT act in a nutshell. Indian J Radiol Imaging. 2012;22(2):133-134.

30. Diamond-Smith N, Rudolph K. The association between uneven sex ratios and violence: evidence from 6 Asian countries. PLoS One. 2018;13(6):e0197516.

31. Bhattacharjya H, Das S, Mog C. Gender preference and factors affecting gender preference of mothers attending Antenatal Clinic of Agartala Government Medica College. Int J Med Sci Public Health. 2014;3:137-139.

32. Chavada M, Bhagyalaxmi A. Effect of socio-cultural factors on the preference for the sex of children by women in Ahmedabad district. HPPI. 2009;32(4):184-189. 